\title{
Preparation of Cerium Oxide-MWCNTs
}

Nanocomposite Bulk Modified Carbon Ceramic Electrode: A Sensitive Sensor for Tamoxifen Determination in Human Serum Samples

\section{Sepideh Shafaei}

Azarbaijan Shahid Madani University

Elyas Hosseinzadeh ( $\sim$ e.hosseinzadeh@sirums.ac.ir)

Sirjan school of medical sciences

Gulsah Saydan Kanberoglu

Yuzuncu Yil University: Van Yuzuncu Yil Universitesi

Balal Khalilzadeh

Tabriz University of Medical Sciences

Rahim Mohammad-Rezaei

Azarbaijan Shahid Madani University https://orcid.org/0000-0002-5015-8717

\section{Research Article}

Keywords: Cerium oxide, MWCNTs, Renewable electrode, Tamoxifen, Electrochemical sensor

Posted Date: March 23rd, 2021

DOI: https://doi.org/10.21203/rs.3.rs-318824/v1

License: (c) (1) This work is licensed under a Creative Commons Attribution 4.0 International License.

Read Full License 


\section{Abstract}

In this study, cerium oxide and multi-walled carbon nanotubes nanocomposite was incorporated into the carbon ceramic electrode $\left(\mathrm{CeO}_{2}-\mathrm{MWCNTS} / \mathrm{CCE}\right)$ as a renewable electrode for the electrocatalytic purposes. To demonstrate capability of the fabricated electrode, determination of Tamoxifen as an important anticancer drug with differential pulse voltammetry technique was evaluated. Linear range, limit of detection and sensitivity of the developed sensor were found to be $0.2-40 \mathrm{nM}, 0.132 \mathrm{nM}$ and $1.478 \mu \mathrm{AnM}^{-1} \mathrm{~cm}^{-2}$, respectively. Ease of production, low cost and high electron transfer rate of $\mathrm{CeO}_{2}-$ MWCNTs/CCE promise it as a novel electro-analytical tool for determination of important species in real samples.

\section{Introduction}

Tamoxifen (TAM) is a nonsteroidal antiestrogen of the triphenylethylene family and belong to selective estrogen receptor modulators drugs which has been widely used for prevention and cure of breast cancer. The most common side effects of TAM are mood swings, constipation, dry skin, headache, bone pain, nausea and vision problems [1]. Therefore, determination of TAM in blood could be helpful in the treatment process of patients. To date, various analytical methods have been used to determine TAM including high-performance liquid chromatography, spectrofluorimetry, spectrophotometry, capillary electrophoresis, voltammetry and etc. [2-8]. Among these methods, electrochemical techniques are broadly used because of their high sensitivity, rapidity, ease of operation, low cost and miniaturization capability.

Among the various materials which are interested in analytical science $[9,10]$, metal oxides especially cerium oxide has been widely used as sensor and biosensor materials because of its hardness, high electrical conductivity, thermal and mechanical stability and catalytic behavior [11-13]. Due to fouling of electrodes during the determination of drugs, there is a critical challenge for utilizing anti-fouling materials, disposable kits, carbon paste and carbon composite electrodes. Carbon ceramic electrode (CCE) is a class of carbon composite electrodes which have has attracted a lot of attention in electrochemistry due to low cost, fast electron transfer rate and renewable surface. Various materials could be entrapped into the sol-gel matrix during the hydrolysis of alkoxysilane and gelation process. Carbon nanotubes with excellent conductivity, high surface area and catalytic activity are appropriate candidate for incorporation into sol-gel matrix for electro-catalytic applications.

Due to high electrocatalytic properties of cerium oxide and multi-walled carbon nanotubes, $\mathrm{CeO}_{2}{ }^{-}$ MWCNTs composites have been prepared by several methods such as hydrothermal, reverse micelles, forced hydrolysis, sol gel process, sonochemistry, microwave and electrochemistry [14-21].

In this study, firstly cerium oxide nanoparticles were immobilized on the surface of functionalized MWCNTs with hydrothermal method in the optimized conditions. The prepared $\mathrm{CeO}_{2}-\mathrm{MWCNTS}$ composites were properly incorporated in the sol-gel matrix of the carbon ceramic electrode and the 
bulkily modified electrode finally named as renewable $\mathrm{CeO}_{2}$-MWCNTs/CCE. To demonstrate electrocatalytic performance of the fabricated electrode, determination of Tamoxifen in human serum samples were studied by differential pulse voltammetry (DPV) technique in details. As the oxidation of TAM and adsorption of oxidation products block the active sites of the electrodes, the prepared $\mathrm{CeO}_{2}-$ MWCNTs/CCE could be polished after each DPV run which results a fresh surface for precise and accurate measurements. Due to low cost, high sensitivity, feasibility and high electrocatalytic properties of the developed renewable sensor, it could be utilized in the development of various electrochemical sensors and biosensors.

\section{Experimental}

\subsection{Reagents and materials}

Tamoxifen, cerium (IV) sulfate, acetic acid, sodium acetate, potassium nitrate, $\mathrm{K}_{3}\left[\mathrm{Fe}(\mathrm{CN})_{6}\right]$, potassium hydroxide, Methyltrimethoxysilane (MTMOS), hydrogen chloride, methanol, graphite, multi-walled carbon nanotubes (MWCNTS), ethanol, ascorbic acid, dopamine and uric acid were purchased from SigmaAldrich Chemical Co. (St. Louis, MO, USA; www.sigmaaldrich.com). The stock solution of $1 \mathrm{mM}$ TAM was prepared in methanol and kept in a refrigerator. In all the experiment distilled water was used as the solvent.

\subsection{Apparatus}

All the electrochemical experiments were carried out with AUTOLAB 204 potentiostat/galvanostat (Metrohm Co., Netherland) with the three-electrode system containing silver/silver chloride (Ag/AgCl) as reference electrode, platinum wire as counter electrode and the prepared CCE, MWCNTs/CCE, $\mathrm{CeO}_{2} / \mathrm{CCE}$ and $\mathrm{CeO}_{2}-\mathrm{MWCNTs} / \mathrm{CCE}$ as the working electrodes. X-ray diffraction and scanning electron microscopy images were obtained using a Bruker AXF (D8 Advance) X-ray powder diffractometer and Phenom ProX scanning electron microscope (Hitachi, Tokyo, Japan) respectively.

\subsection{Preparation of the functionalized MWCNTs}

For treatment and functionalization of MWCNTs, $4 \mathrm{~g}$ of MWCNTs was refluxed in $10 \mathrm{ml}$ of $2 \mathrm{M} \mathrm{H}_{2} \mathrm{SO}_{4}$ and $6 \mathrm{M} \mathrm{HNO}_{3}$ solution for $24 \mathrm{~h}$. The obtained precipitates were collected by centrifuged and washed several times with water and ethanol (1:1). Finally, the obtained precipitates were collected and allowed to dry for $48 \mathrm{~h}$ at room temperature $\left(25^{\circ} \mathrm{C}\right)$.

\subsection{Preparation of the $\mathrm{CeO}_{2}-\mathrm{MWCNTS} / \mathrm{CCE}$}

In order to prepare $\mathrm{CeO}_{2}-\mathrm{MWCNTs}$ nanocomposite, $2 \mathrm{~g}$ of MWCNTs and $0.05 \mathrm{~g}$ of cerium (IV) sulfate were dispersed in $10 \mathrm{ml}$ distilled water and the $\mathrm{pH}$ was adjusted to 10. Afterward the suspension was placed in ultrasonic bath for $120 \mathrm{~min}$ in the controlled temperature of $40^{\circ} \mathrm{C}$. The obtained precipitates were 
collected by centrifuged and washed via distilled water and ethanol (1:1) for several times. Finally the obtained black powder calcined at $500{ }^{\circ} \mathrm{C}$ for $2 \mathrm{~h}$.

The obtained $\mathrm{CeO}_{2}-\mathrm{MWCNTs}$ nanocomposite was utilized as modifier in the structure of ceramic carbon electrode as follow: $0.9 \mathrm{ml}$ methanol was mixed with $0.6 \mathrm{ml}$ MTMOS and $0.6 \mathrm{ml} 0.1 \mathrm{M}$ hydrochloric acid as catalyst and was stirred using a magnetic stirrer about $20 \mathrm{~min}$ until the sol was changed to a milky gel. Afterward, $0.24 \mathrm{~g}$ graphite powder and $0.06 \mathrm{~g} \mathrm{CeO}_{2}$-MWCNTs powders were added to the obtained gel. The resulting mixture was mixed for another 5 min using a spatula until a uniform paste was obtained. Finally, the obtained product was molded into a Teflon tube and dried at laboratory for $24 \mathrm{~h}$. A copper wire was used for electric current and a Teflon tape as insulation on a ceramic carbon electrode. The surface of prepared electrode was polished with emery paper grade 2500 and washed with distilled water. The prepared $\mathrm{CeO}_{2}-\mathrm{MWCNTS/CCE}$ could be polished several times after the electrochemical studies and a new surface with characteristics similar to the first electrode will be obtained.

\section{Results And Discussion}

\subsection{Characterization of the $\mathrm{CeO}_{2}-\mathrm{MWCNTS} / \mathrm{CCE}$}

To study the morphology of the prepared electrodes, SEM images of the electrodes in various magnifications were obtained. Fig. 1A shows the SEM image of CCE with magnification of 30000 with

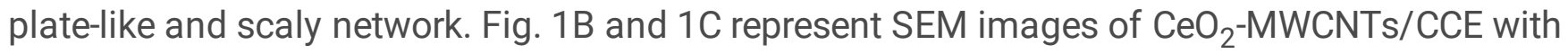
magnifications of 30000 and 80000 respectively. According to these images $\mathrm{CeO}_{2}-\mathrm{MWCNTS}$ nanocomposite were uniformity distributed on the surface of CCE and MWCNTs were properly covered the surface of $\mathrm{CeO}_{2}$. The prepared electrode could be polished after each electroanalytical experiment to avoid negative effect of previous studies which resolve memory effect and fouling of electrode as the important problems in analytical studies.

XRD pattern of the bulk modified $\mathrm{CeO}_{2}-\mathrm{MWCNTs} / \mathrm{CCE}$ was shown in Fig. S1. The diffraction peaks at $26.4^{\circ}, 27.5^{\circ}, 32.1^{\circ}, 46.4^{\circ}, 56.5^{\circ}, 59.8^{\circ}, 69.9^{\circ}, 76.4^{\circ}$ and $78.2^{\circ}$ correspond to (002), (111), (200), (220), (311), (222), (400), (331) and (420) planes of $\mathrm{CeO}_{2}$. The XRD peaks have good consistency with standard diffraction patterns (JCPDS) of the $\mathrm{CeO} 2$ with cubic fluorite structure [22]. The broadening of diffraction peaks at about $26^{\circ}$ and $44^{\circ}$ could be assigned to the (002) and (100) planes of the hexagonal graphite structure of the MWCNTs [23].

\subsection{Electrochemical behavior of the $\mathrm{CeO}_{2}-\mathrm{MWCNTs} / \mathrm{CCE}$}

Electrochemical performance of the bare $\mathrm{CCE}, \mathrm{CeO}_{2} / \mathrm{CCE}, \mathrm{MWCNTs} / \mathrm{CCE}$ and $\mathrm{CeO}_{2}-\mathrm{MWCNTS} / \mathrm{CCE}$ were studied with cyclic voltammetry technique in $0.01 \mathrm{M}\left[\mathrm{Fe}(\mathrm{CN})_{6}\right]^{3-}$ containing $0.1 \mathrm{M}$ acetate buffer solution with the $\mathrm{pH}$ of 4.2 (Fig. 2). As can be seen, the bulk modified $\mathrm{CeO}_{2}-\mathrm{MWCNTs} / \mathrm{CCE}$ (curve d) has better electrocatalytic activity (less peak to peak separation and more anodic and cathodic currents) in 
comparison with CCE (curve a), $\mathrm{CeO}_{2} / \mathrm{CCE}$ (curve b) and MWCNTs/CCE (curve c) due to synergic effect of $\mathrm{CeO}_{2}$ and $\mathrm{MWCNTs}$ in the last electrode. The results represent higher electron transfer rate performance of the $\mathrm{CeO}_{2}$-MWCNTs/CCE for electroanalytical purposes.

To calculate the active surface area of the prepared electrodes, cyclic voltammograms (CVs) of the CCE and $\mathrm{CeO}_{2}-\mathrm{MWCNTS} / \mathrm{CCE}$ were recorded in different scan rates in $0.01 \mathrm{M}\left[\mathrm{Fe}(\mathrm{CN})_{6}\right]^{3-}$ and $0.1 \mathrm{M}$ acetate buffer solution the with pH of 4.2 (Fig. S2A and Fig. S3A). The corresponding anodic and cathode peak currents vs. square root of the scan rate proportional were depicted in Fig. S2B and S3B, respectively. The suitable linearity of the last curves indicate that the electrochemical process is controlled by diffusion. Active surface area of the bare and modified electrode could be calculated from the slope of the peak currents in terms of the square root of the scan rate utilizing the Randles-Sevcik equation $[24,25]$ :

$$
I_{\mathrm{pa}}=\left(2.69 \times 10^{5}\right) \mathrm{n}^{\frac{3}{2}} A D^{\frac{1}{2}} C v^{\frac{1}{2}} \quad(\mathrm{Eq} .1)
$$

In this equation $A$ is the active surface area of electrode $\left(\mathrm{cm}^{2}\right), n$ represents the number of electrons in the reaction, $D$ is the diffusion coefficient of $\left[\mathrm{Fe}(\mathrm{CN})_{6}\right]^{3-}\left(\mathrm{D}=7.6 \times 10^{-6} \mathrm{~cm}^{2} \mathrm{~s}^{-1}\right)$, and $C$ signify the concentration of hexacyanoferrate. According to this theory the active surface of CCE and $\mathrm{CeO}_{2}-$ MWCNTs/CCE were calculated to be 0.43 and $0.97 \mathrm{~cm}^{2}$ indicating a significant increase in the active surface area of the prepared modified electrode.

\subsection{Electrochemical behavior of TAM on the bulk modified $\mathrm{CeO}_{2}-\mathrm{MWCNTs} / \mathrm{CCE}$}

To evaluate the performance of the bulk modified $\mathrm{CeO}_{2}-\mathrm{MWCNTs} / \mathrm{CCE}$ in electrocatalytic applications, determination of TAM as an important anticancer drug in human serum samples was studied. Fig. 3 shows the CVs of CCE, $\mathrm{CeO}_{2}$ /CCE, MWCNTs/CCE and $\mathrm{CeO}_{2}-\mathrm{MWCNTS/CCE}$ in the absence (curves a-d) and presence of $8 \mu \mathrm{M}$ (curves e-h) of TAM in $0.1 \mathrm{M}$ acetate buffer solution with the $\mathrm{pH}$ of 4.2. As can be seen, oxidation peak current of the modified electrode has improved remarkably in comparison with other electrode revealing high sensitivity and high electrocatalytic performance of $\mathrm{CeO}_{2}-\mathrm{MWCNTS} / \mathrm{CCE}$. Also, the potential of oxidation peak as well as starting oxidation potential of the TAM was shifted to less positive potential proving the improved performance of the $\mathrm{CeO}_{2}-\mathrm{MWCNTs} / \mathrm{CCE}$.

To obtain more information about the oxidation of TAM on the electrode surface, cyclic voltammograms of $8 \mu \mathrm{M}$ TAM in $0.1 \mathrm{M}$ acetate buffer solution ( $\mathrm{pH} 4.2)$ at different sweep rates were recorded with $\mathrm{CeO}_{2}$ MWCNTs/CCE (Fig. 4A). As can be seen, by increasing the sweep rate, the anodic peak currents increase linearly (Fig. 4B) indicating that the adsorption of TAM on the $\mathrm{CeO}_{2}-\mathrm{MWCNTS} / \mathrm{CCE}$ is dominant electrode process.

To investigate the effect of solution $\mathrm{pH}, \mathrm{CVs}$ of $\mathrm{CeO}_{2}-\mathrm{MWCNTs} / \mathrm{CCE}$ in various $\mathrm{pHs}$ in the $0.1 \mathrm{M}$ acetate buffer solution in the presence of $8 \mu \mathrm{M}$ TAM were recorded (Fig. 5) and dependency of pH to the oxidation peak potential (Inset of Fig. 5) was studied. As can be seen, by increase of pH, the oxidation 
potential of TAM was shifted to less positive potentials indicating the involvement of proton in the electrode reaction. The association between the peak potential and $\mathrm{pH}$ value could be expressed by the following equation:

$$
\left.E_{\mathrm{p}}(\mathrm{mV})=0.0503 \mathrm{pH}+0.7885 \quad \text { (Eq. } 2\right)
$$

The slope of the Ep vs. $\mathrm{pH}$ indicates that equivalent number of electrons and protons involved in the TAM oxidation.

Acceding to this study, the highest current intensity was observed in the $\mathrm{pH}$ value of 4.2. Destruction of $\mathrm{CeO}_{2}$ in more acidic media (below $\mathrm{pH}$ of 4 ) and also insolubility of TAM in more alkali media (pKa=8.85) are the main reasons to conclude $\mathrm{pH}=4.2$ as the optimum $\mathrm{pH}$ for the sensitive and accurate determination of TAM.

\subsection{Analytical studies and determination results of TAM}

Fig. S4 represents the $\mathrm{CVs}$ of the $\mathrm{CeO}_{2}-\mathrm{MWCNTs} / \mathrm{CCE}$ in the $0.1 \mathrm{M}$ acetate buffer solution $(\mathrm{pH}=4.2)$ in various concentrations of TAM $(4.5 \mu \mathrm{M}$ to $10 \mu \mathrm{M})$. As can be seen, by increasing the concentration of TAM, the peak currents were increased linearly $\left(R^{2}=0.9992\right)$ proving appropriate potential of the developed electrode for the sensitive determination of TAM.

To determine low concentrations of TAM drug in real samples, differential pulse voltammetry (DPV) as a sensitive electrochemical technique was utilized. Fig. 6A shows the DPVs of the $\mathrm{CeO}_{2}-\mathrm{MWCNTs} / \mathrm{CCE}$ in the optimum conditions ( $0.1 \mathrm{M}$ acetate buffer, $\mathrm{pH}$ of 4.2 , step potential $0.005 \mathrm{~V}$, modulation amplitude $0.025 \mathrm{~V}$ and modulation time $0.05 \mathrm{~s}$ ) in different concentrations of TAM. The corresponding calibration curve was shown Fig. $6 \mathrm{~B}$ with the linear range of 0.2 to $40 \mathrm{nM}$, sensitivity of $0.176 \mu \mathrm{Am}^{-1}$ (or $16.8 \mathrm{nA}$ $\mathrm{nM}^{-1} \mathrm{~cm}^{-2}$ ) and detection limit of the $0.132 \mathrm{nM}$ (in the signal to noise of 3). The figure of merits of the $\mathrm{CeO}_{2}-\mathrm{MWCNTS} / \mathrm{CCE}$ in measurement of TAM was compared with various articles [26-30] and the results were shown in Table 1. According to these the developed electrode has improved analytical response to TAM due to synergistic effect of MWCNTs and $\mathrm{CeO}_{2}$ as ideal conductive and electrocatalyst which bulkily decorated in the CCE with high stability.

\subsection{Interference studies}

In order to examine the interference of some important species, DPV of the TAM in the presence of common interferences were studied. Fig. 7 shows the DPV of the $\mathrm{CeO}_{2}-\mathrm{MWCNTS} / \mathrm{CCE}$ in the optimum conditions in the presence of $10 \mathrm{nM}$ TAM and $1 \mu \mathrm{M}$ ascorbic acid (AA), $2 \mu \mathrm{M}$ uric acid (UA) and $5 \mu \mathrm{M}$ dopamine (DA). As can be seen, the peak potentials of the AA, UA and UA are $0.18 \mathrm{~V}, 0.32 \mathrm{~V}$ and $0.45 \mathrm{~V}$ which are more different than TAM oxidation potential $(0.95 \mathrm{~V})$. The inset of Fig. 7 shows the DPV of the $\mathrm{CeO}_{2}$-MWCNTs/CCE in the same conditions in the absence of interferences. Based on the results, it can be concluded that TAM could be determined with $\mathrm{CeO}_{2}-\mathrm{MWCNTS} / \mathrm{CCE}$ in the presence of AA, DA and UA 
without any effect on changing the TAM signal. Also, the interference of 1000 -fold of $\mathrm{K}^{+}, \mathrm{Mg}^{2+}, \mathrm{Ca}^{2+}$, $\mathrm{NO}_{3}{ }^{-}, \mathrm{Cl}^{-}$, lactose, fructose and glucose were studied. The results showed that the developed bulk modified $\mathrm{CeO}_{2}-\mathrm{MWCNTS} / \mathrm{CCE}$ has suitable selectivity for TAM measurement (error of less than $\pm 5 \%$ ) promising it for real sample analysis.

\subsection{Analysis of human blood serum sample}

To evaluate the capability of the developed sensor in clinical analysis, determination of TAM in human blood serum as a complex media was investigated. The serum samples were prepared as follow: $2.5 \mathrm{ml}$ of serum sample was diluted with $2.5 \mathrm{ml}$ of methanol and the resultant mixture was centrifuged at 8000 rpm for 10 min to precipitate the suspended matter and protein. The isolated solution was kept at $-20{ }^{\circ} \mathrm{C}$ until analysis. According to this study, TAM was not detected in healthy human serum. To explore the accuracy of the developed method, determined value of TAM was spiked to the serum samples and recoveries of the measurements were calculated. The results of measurements, relative standard deviations (RSD) and recoveries were presented in Table 2. The recoveries of 99.80 and 99.87 and also RSD values of 1.8 and 1.4 indicate suitable validity of the $\mathrm{CeO}_{2}-\mathrm{MWCNTS/CCE}$ for the determination of TAM in serum samples.

\subsection{Investigation of the reproducibility of the $\mathrm{CeO}_{2}-\mathrm{MWCNTs} / \mathrm{CCE}$}

Fouling of electrodes during the electrochemical studies decreases the performance of electrodes. The bulk modified $\mathrm{CeO}_{2}-\mathrm{MWCNTS}$ /CCE could be simply polished with polishing papers and a new surface characteristics similar to the first electrode will be obtained. The preparation reproducibility of the developed electrode was examined by determination of $10 \mathrm{nM}$ TAM with five independently prepared electrode with DPV method in the optimized conditions. According to this study, RSD value was calculated to be $4.6 \%$. A similar experiment was done to study the polishing reproducibility of the electrode. For this purpose, the electrode was polished after each DPV experiment and the peak currents after the reduction of background current was recorded. The RSD value of $4.1 \%$ proves the reproducibility of the electrode after several polishing steps. The prepared electrode is stable to be stored in room temperature more than 6 month and suitable RSDs were obtained (lowed than $4.5 \%$ in DPV and 3.9\% in cyclic voltammetry). The results showed the unique potential of the developed sensor for commercial and clinical goals.

\section{Conclusion}

$\mathrm{CeO}_{2}-\mathrm{MWCNTS}$ nanocomposite was simply prepared and incorporated to the CCE structure which resulted a polishable electrode for electrochemical studies. The prepared electrode was characterized carefully and proved to have high electron transfer rate ability and electrocatalytic features. The electrode was successfully utilized for anticancer TAM drug measurement in serum samples with DPV technique. High sensitivity, selectivity and wide linear range of the electrode as well as reproducibility, stability and low cost promised the $\mathrm{CeO}_{2}$-MWCNTs/CCE for clinical purposes. 


\section{Declarations}

\section{Acknowledgments}

The authors gratefully acknowledge the Sirjan School of Medical Sciences and Research Council of Azarbaijan Shahid Madani University for financial support.

\section{Data Availability Statement}

The data that support the findings of this study are available from the corresponding authors upon reasonable request.

\section{Conflict-of-interest statement}

The authors have no conflicts of interest to declare. All co-authors have seen and agree with the contents of the manuscript and there is no financial interest to report. We certify that the submission is original work and is not under review at any other publication.

\section{References}

[1] G. Yang, S. Nowsheen, K. Aziz, A.G. Georgakilas, Pharmacol. Therapeut. 139, 392-404 (2013)

[2] H. Sereshti, S. Bakhtiari, H. Najarzadekan, S. Samadi, J. Sep. Sci. 40, 3383-3391 (2017)

[3] L.Y. Thang, H.H. See, J.P. Quirino, Electrophoresis 37, 1166-1169 (2016)

[4] M.V. Antunes, S. Raymundo, V. de Oliveira, D.E. Staudt, G. Gössling, G.P. Peteffi, J.V. Biazús, J.A. Cavalheiro, M. Tre-Hardy, A. Capron, V. Haufroid, P. Wallemacq, G. Schwartsmann, R. Linden, Talanta 132, 775-784 (2015)

[5] S.F. Teunissen, H. Rosing, A.H. Schinkel, J.H.M. Schellens, J.H. Beijnen, Anal. Chim. Acta 683, 21-37 (2010)

[6] F.P. Gomes, P.L. Garcia, Talanta 101, 495-503 (2012)

[7] P. Daneshgar, P. Norouzi, M.R. Ganjali, H.A. Zamani, Talanta 77, 1075-1080 (2009)

[8] C.S.P. Sastry, J.S.V.M.L. Rao, K.R. Rao, Talanta 42, 1479-1485 (1995)

[9] E. Hosseinzadeh, H. Ravan, A. Mohammadi, H. Pourghadamyari, Talanta 216, 120913 (2020)

[10] H. Ravan, A. Norouzi, N. Sanadgol, E. Hosseinzadeh, Microchim. Acta 187, (2020) 392.

[11] Y. Zhai, S. Zhang, H. Pang, Mater. Lett. 61, 1863-1866 (2007)

[12] P. Borker, A. Salker, Mater. chem. phys. 103, 366-370 (2007) 
[13] A. Xie, F. Tao, T. Li, L. Wang, S. Chen, S. Luo, C. Yao, Electrochim. Acta 261, 314-322 (2018)

[14] J.-D. Qiu, S.-G. Cui, R.-P. Liang, Microchim Acta 171, 333-339 (2010)

[15] C. Li, N. Sun, J. Ni, J. Wang, H. Chu, H. Zhou, M. Li, Y. Li, J. Solid State Chem. 181, 2620-2625 (2008)

[16] J. Wei, J. Ding, X. Zhang, D. Wu, Z. Wang, J. Luo, K. Wang, Mater. Lett. 59, 322-325 (2005)

[17] D. Zhang, T. Yan, L. Shi, C. Pan, J. Zhang, Appl. Surf. Sci. 255, 5789-5794 (2009)

[18] Z. Sun, X. Zhang, B. Han, Y. Wu, G. An, Z. Liu, S. Miao, Z. Miao, Carbon 45, 2589-2596 (2007)

[19] Y. Li, J. Ding, J. Chen, C. Xu, B. Wei, J. Liang, D. Wu, Mater. res. bull. 37, 313-318 (2002)

[20] S. Harikrishna, A.R. Robert, H. Ganja, S. Maddila, S.B. Jonnalagadda, Appl. Organomet. Chem. 34, e5796 (2020)

[21] C. Liu, L. Zhang, L. Sun, W. Wang, Z. Chen, Int. J. Hydrog. Energy 45, 8558-8567 (2020)

[22] D. Parimi, V. Sundararajan, O. Sadak, S. Gunasekaran, S.S. Mohideen, A. Sundaramurthy, ACS Omega 4, 104-113 (2019)

[23] A. Awadallah-F, S. Al-Muhtaseb, Sci. Rep. 10, 4878 (2020)

[24] T.R.L.C. Paixão, ChemElectroChem 7, 3414-3415 (2020)

[25] Y.I. Kuzin, P.L. Padnya, I.I. Stoikov, V.V. Gorbatchuk, D.I. Stoikov, A.I. Khadieva, G.A. Evtugyn, Electrochim. Acta 345, 136195 (2020)

[26] R. Jain, Vikas, K. Radhapyari, Drug Test. Anal. 3, 743-747 (2011)

[27] X.-x. Guo, Z.-J. Song, X.-j. Tian, J.-f. Song, Anal. Lett. 41, 1225-1235 (2008)

[28] H.M. Moghaddam, H. Beitollahi, G. Dehghannoudeh, H. Forootanfar, J. Electrochem. Soc. 164, B372B376 (2017)

[29] G.S. Kanberoglu, F. Coldur, C. Topcu, O. Cubuk, IEEE Sens. J. 15, 6199-6207 (2015)

[30] E.A. Khudaish, Microchem. J. 152, 104327 (2020).

\section{Tables}

Table 1 Comparison table for the determination of TAM via various electrodes. 


\begin{tabular}{|lllll|}
\hline Electrode material & Method & LOD & Linear range & Ref. \\
\hline Gold electrode & DPV & $9.40 \mathrm{ng} \mathrm{mL}^{-1}$ & $1.0-6.0 \mu \mathrm{g} \mathrm{m}^{-1}$ & [26] \\
\hline Carbon paste electrode & SWV & $1.0 \times 10^{-10} \mathrm{M}$ & $7.0 \times 10^{-10}-3.0 \times 10^{-8} \mathrm{M}$ & {$[27]$} \\
\hline Graphene/ds-DNA /SPE & DPV & $1.0 \times 10^{-7} \mathrm{M}$ & $8.0 \times 10^{-7}-8.5 \times 10^{-5} \mathrm{M}$ & {$[28]$} \\
\hline PVC $^{\text {b-membrane }}$ & ISE & $7.3 \times 10^{-6} \mathrm{M}$ & $9.1 \times 10^{-6}-1.0 \times 10^{-3} \mathrm{M}$ & [29] \\
\hline VOx-GCE $^{\mathrm{C}}$ & Amperometry & $389 \mathrm{nM}$ & $50-250 \mu \mathrm{M}$ & [30] \\
\hline $\mathrm{CeO}_{2}$-MWCNTs/CCE & DPV & $0.132 \mathrm{nM}$ & $0.2-40 \mathrm{nM}$ & This work \\
\hline
\end{tabular}

a Screen printed electrode

${ }^{\mathrm{b}}$ poly(vinylchloride)

${ }^{\mathrm{c}}$ Ion selective electrode

Table 2 Determination of TAM results in human blood serum sample.

\begin{tabular}{c|cccc|}
\hline Sample & Added (nM) & founded (nM) & RSD (\%) & Recovery (\%) \\
\hline $\begin{array}{c}\text { Human } \\
\text { blood } \\
\text { serum }\end{array}$ & - & ND & 1.11 & - \\
\cline { 2 - 5 } & 0.4 & 0.38 & 1.8 & 99.80 \\
\cline { 2 - 5 } & 0.6 & 0.45 & 1.4 & 99.87 \\
\hline
\end{tabular}

\section{Figures}




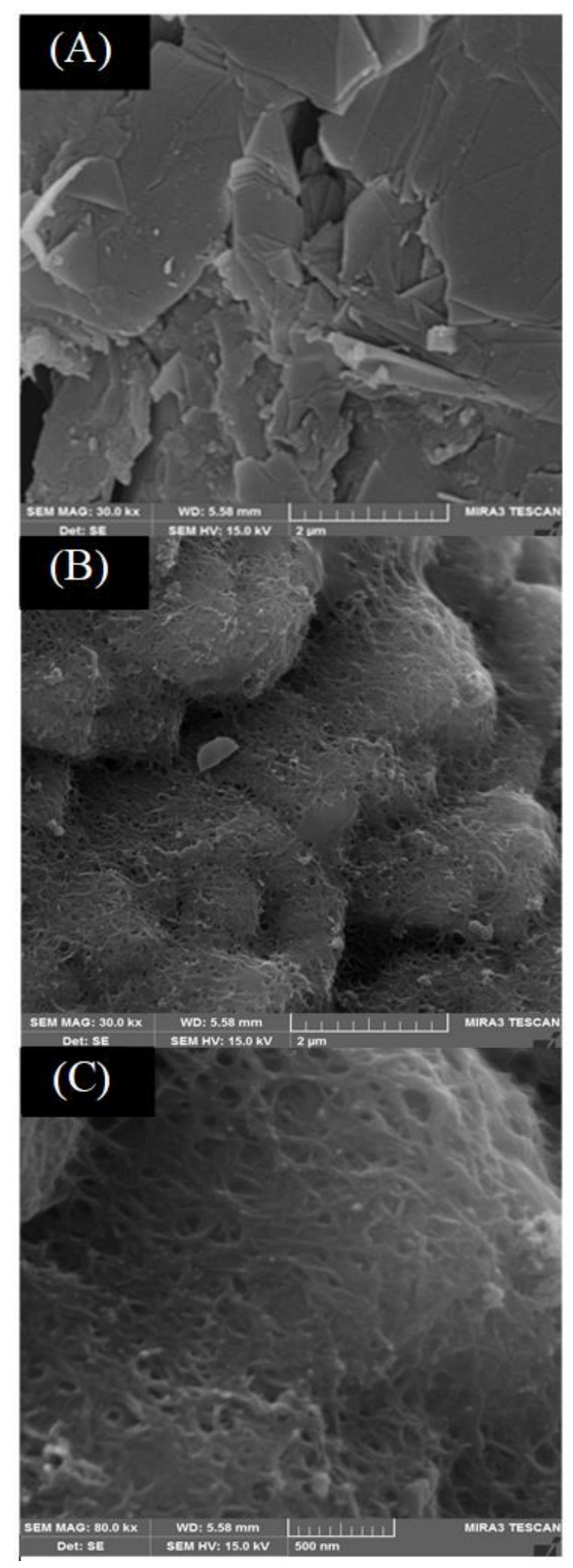

\section{Figure 1}

SEM images of CCE with magnification of 30000 (A) and CeO2-MWCNT/CCE with magnifications of 30000 (B) and 80000 (C). 


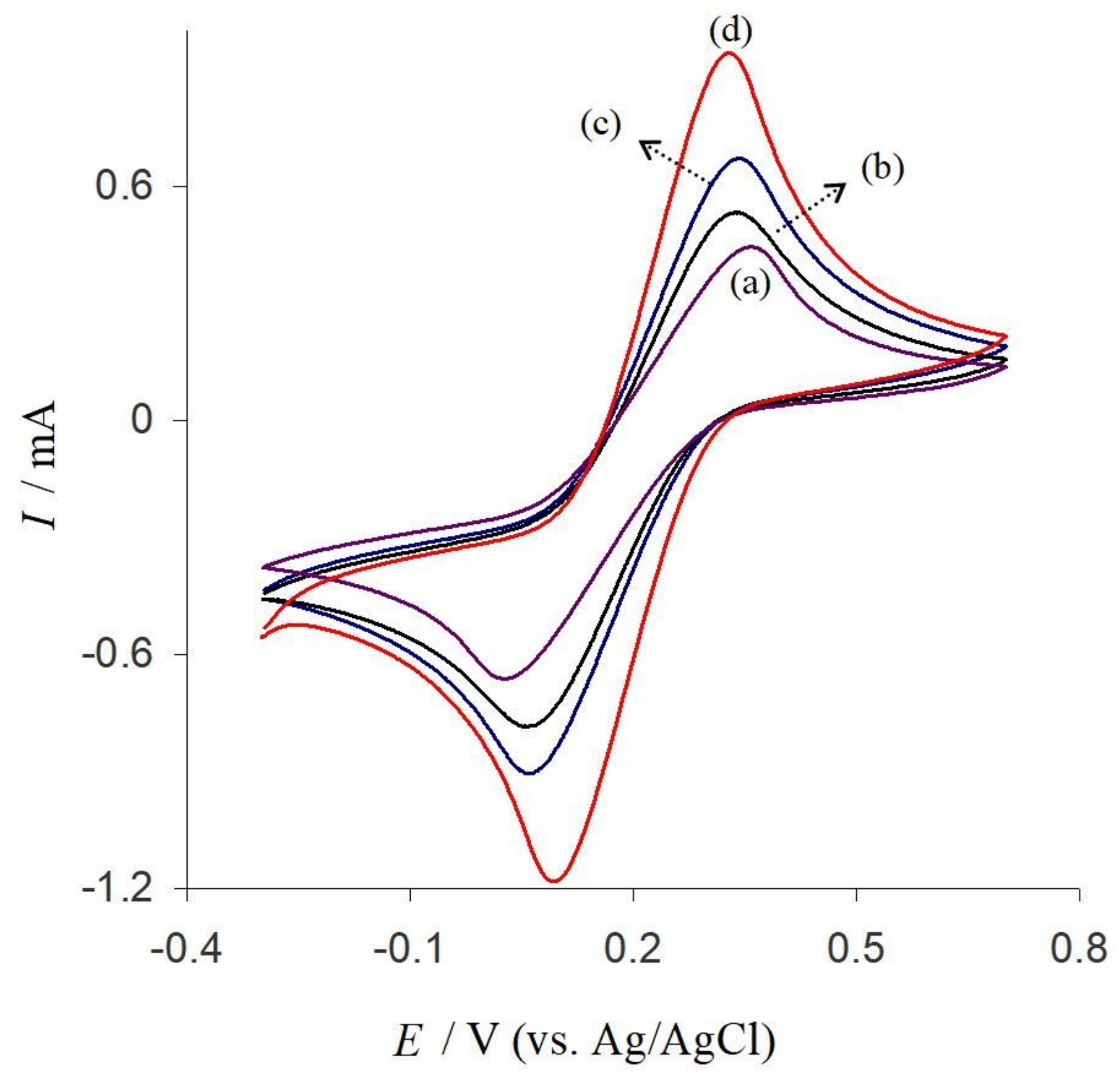

Figure 2

CVs of (a) Bare-CCE, (b) CeO2/CCE, (C) MWCNT/CCE, and (d) Ce02-MWCNT/CCE in the presence of 0.01 $\mathrm{M}[\mathrm{Fe}(\mathrm{CN}) 6] 3-$ and $0.1 \mathrm{M}$ acetate buffer solution with scan rate of $50 \mathrm{mV} \mathrm{s}-1$. 


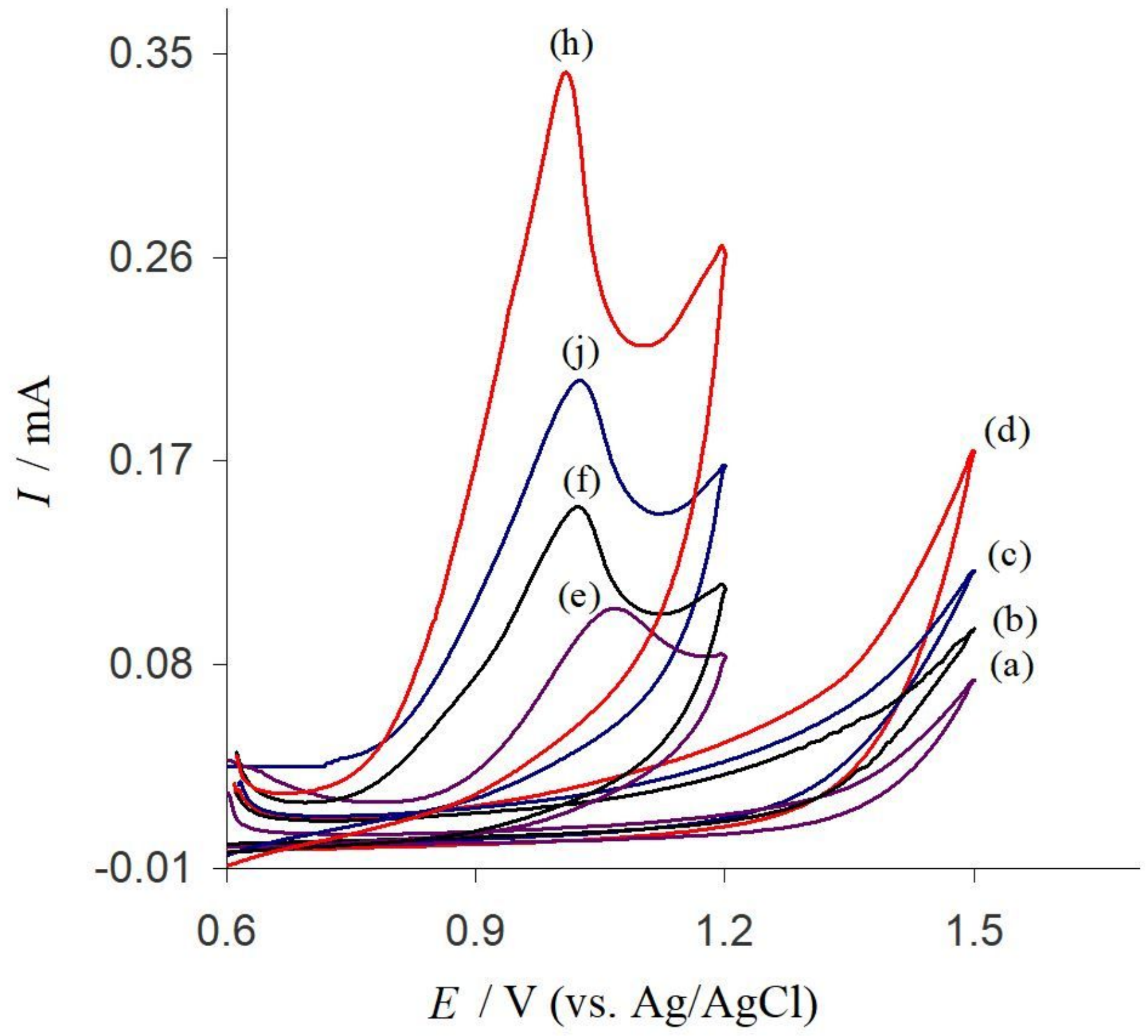

Figure 3

CVs of CCE, CeO2/CCE, MWCNT/CCE and CeO2-MWCNT/CCE in $0.1 \mathrm{M}$ acetate buffer solution in the absence (curves a-d) and presence (curves e-h) of $8 \mu \mathrm{M}$ TAM, scan rate $50 \mathrm{mV} \mathrm{s}-1$ and pH 4.2. 

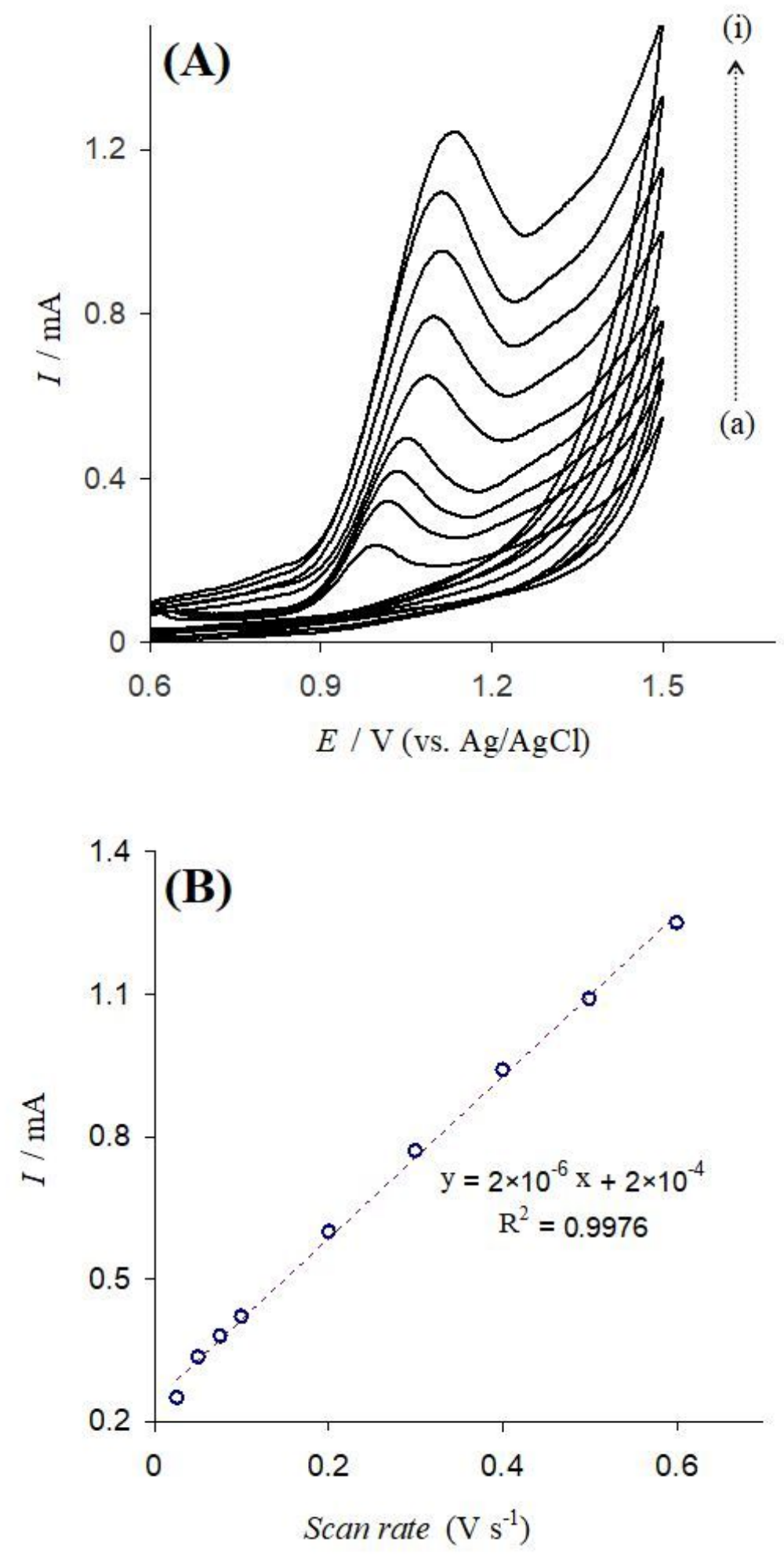

Figure 4

(A) CVs of CeO2-MWCNT/CCE in the presence of $8 \mu \mathrm{M}$ TAM in $0.1 \mathrm{M}$ acetate buffer solution at different scan rates of $25,50,75,100,200,300,400,500$ and $600 \mathrm{mV} \mathrm{s}-1 ;$ (B) Variation of peak currents vs. scan rate. 


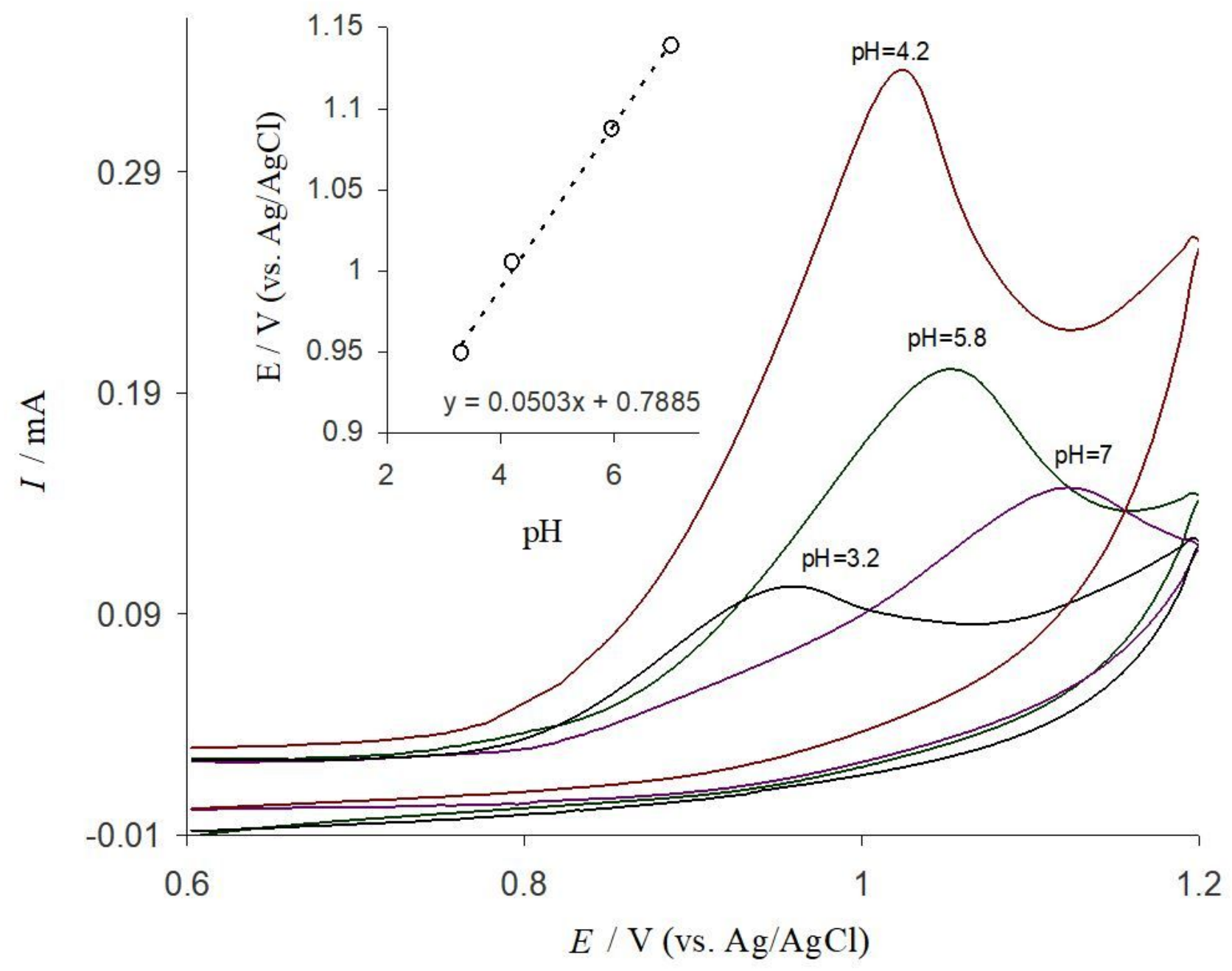

Figure 5

CVs obtained at CeO2-MWCNT/CCE in a $0.1 \mathrm{M}$ acetate buffer containing $8 \mu \mathrm{M}$ TAM at different pHs; Inset shows the plot of Ep vs. pH values. 


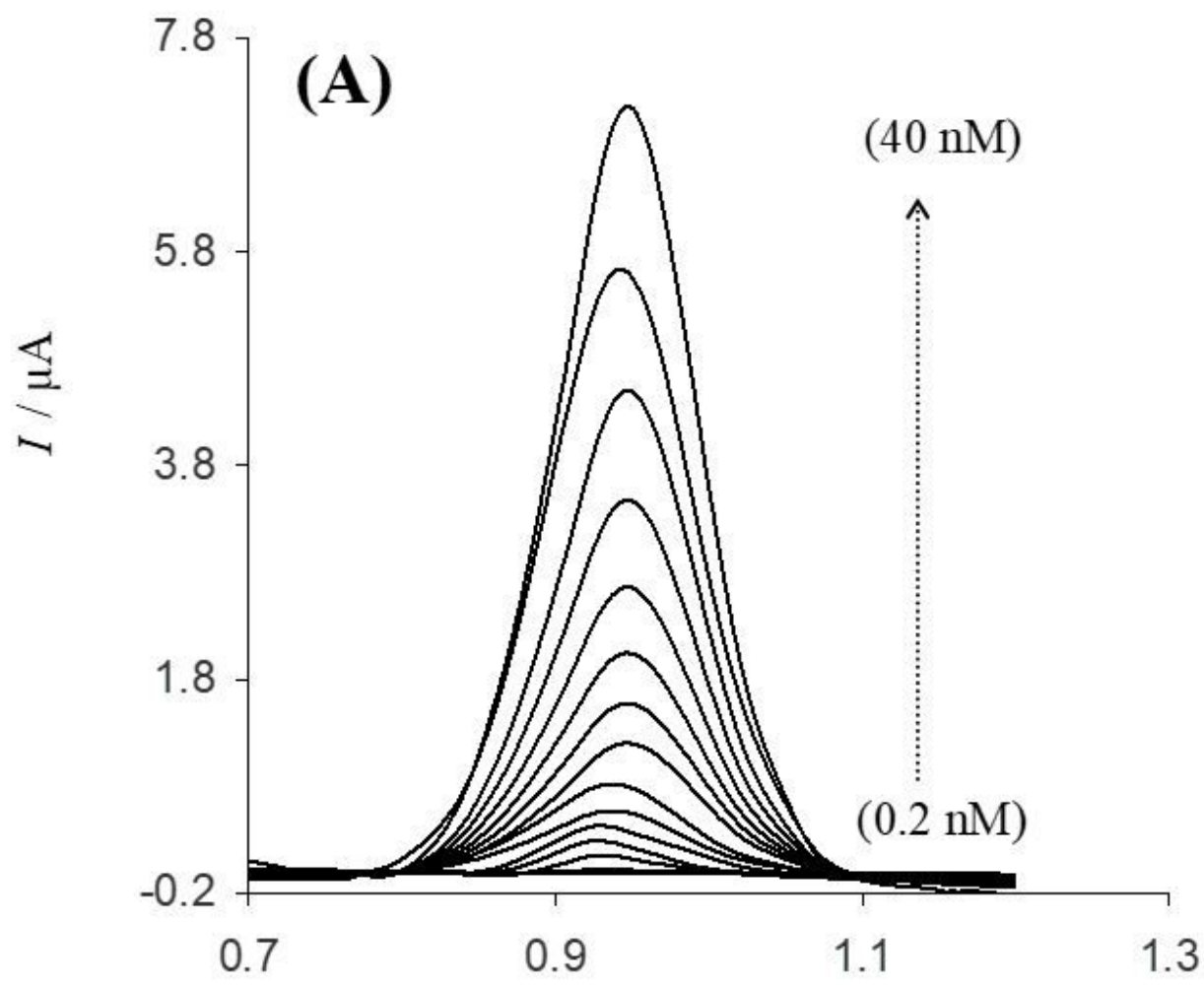

$E / \mathrm{V}$ (vs. $\mathrm{Ag} / \mathrm{AgCl})$

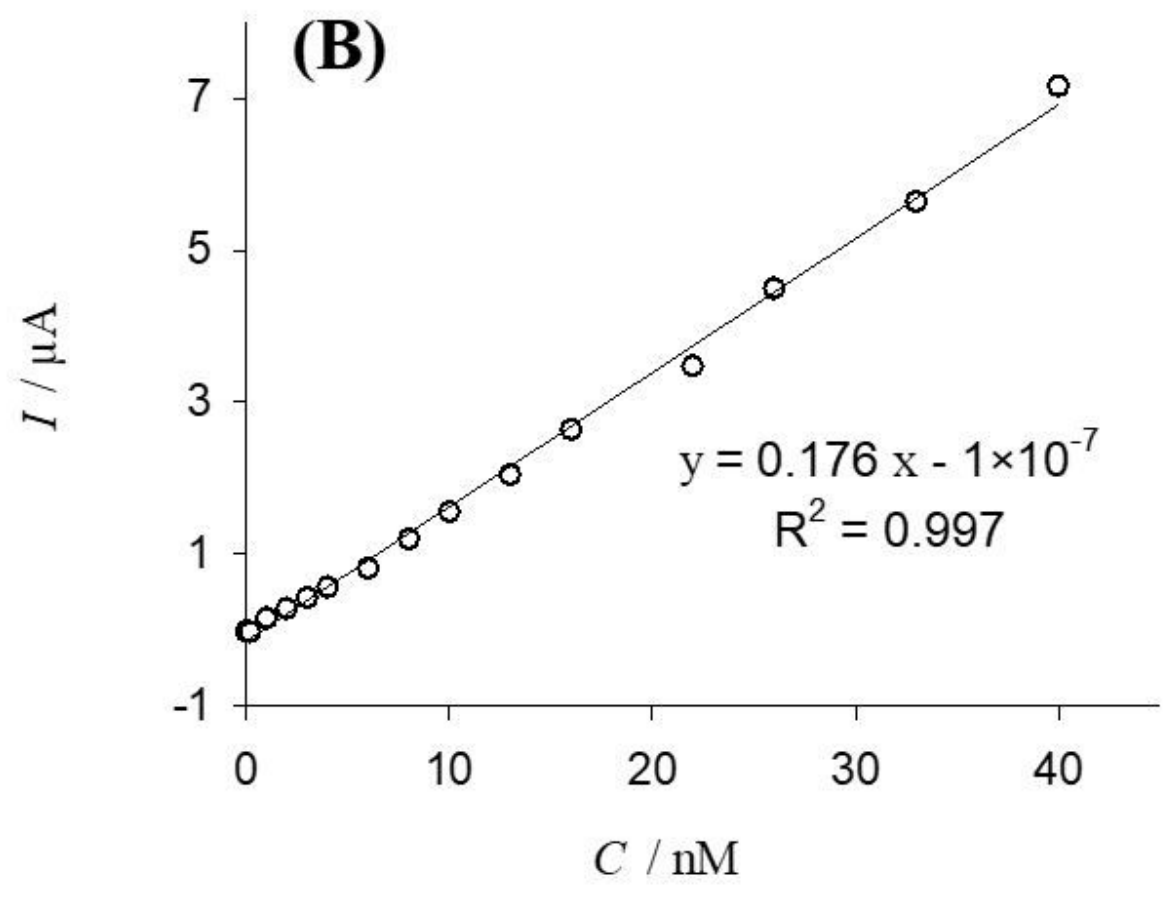

Figure 6

(A) DPVs of TAM in the different concentrations of $0,0.2,1,2,3,4,6,8,10,13,16,22,26,33$ and $40 \mathrm{nM}$ in $0.1 \mathrm{M}$ acetate buffer (( $\mathrm{pH} 4.2)$ and $(\mathrm{B})$ the corresponding calibration curve. 


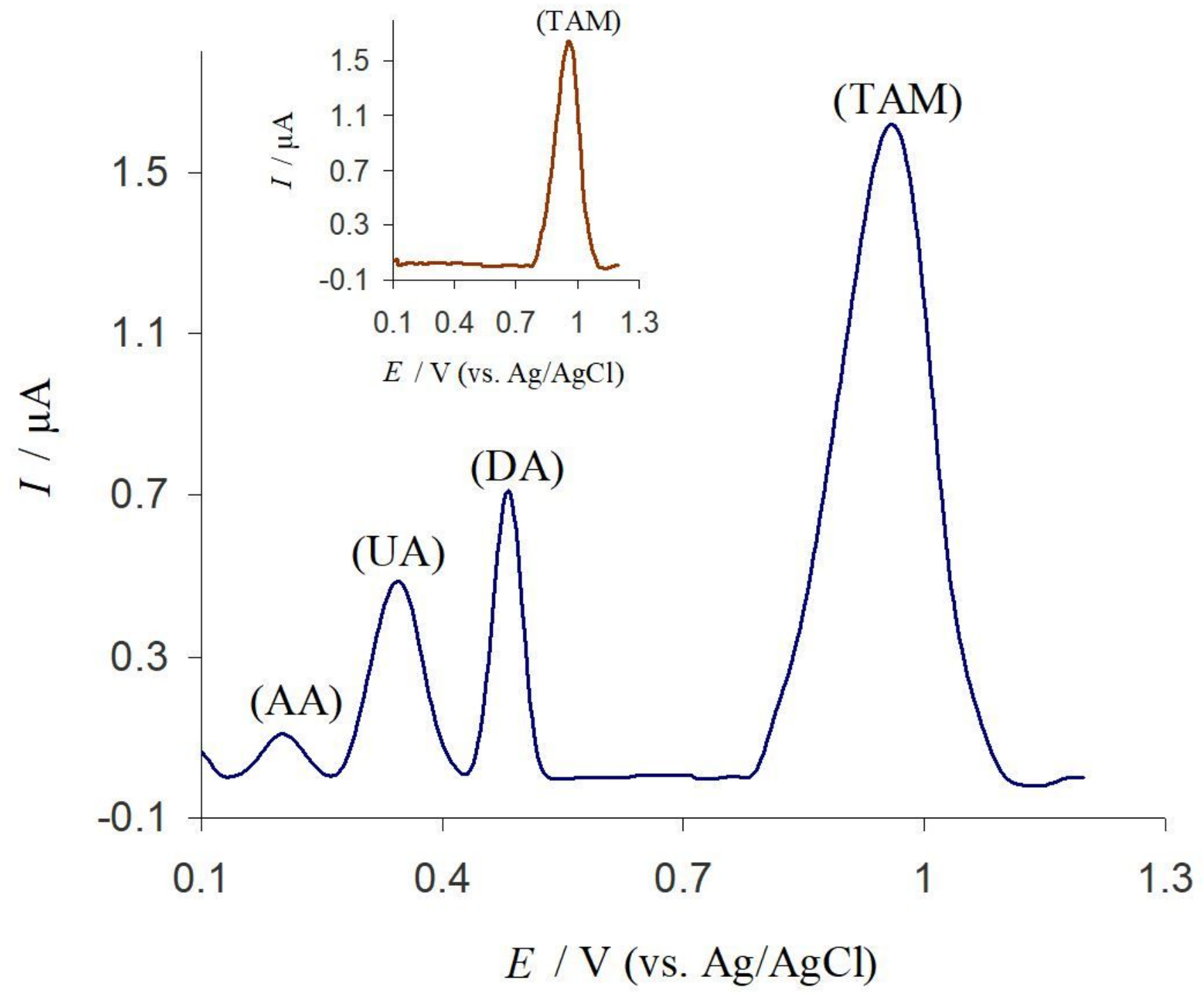

Figure 7

DPV of CeO2-MWCNT/CCE in $0.1 \mathrm{M}$ acetate buffer solution ( $\mathrm{pH}$ 4.2) containing $10 \mathrm{nM}$ TAM, $1 \mu \mathrm{M}$ of AA, $2 \mu \mathrm{M} \cup A$ and $5 \mu \mathrm{M}$ DA; Inset represents the DPV of the electrode in a solution containing $10 \mathrm{nM}$ TAM.

\section{Supplementary Files}

This is a list of supplementary files associated with this preprint. Click to download.

- sfig1.jpg

- sfig2.jpg

- sfig3.jpg

- sfig4.jpg 